\title{
POLÍTICAS FEMINISTAS DO ABORTO
}

\author{
LUCILA SCAVONE \\ Universidade Estadual Paulista
}

\begin{abstract}
Resumo: Os debates e as ações feministas em prol da liberalização do aborto no Brasil foram marcados por avanços, recuos e, sobretudo, por inúmeras negociações políticas. Da omissão da palavra "aborto", em meados dos anos 70, à opção política pela descriminalização e pela realização dos casos previstos por lei, observa-se uma vocação política do feminismo brasileiro para a negociação. Conclui-se que essas negociações tiveram mais êxito em nível político do que social, pois não lograram alcançar e sensibilizar camadas mais amplas da população.
\end{abstract}

Palavras-chave: aborto no Brasil; feminismo e aborto; direitos individuais e aborto; liberação do aborto; feminismo e política.

Este ensaio tem como objetivo discutir as políticas feministas relacionadas ao aborto - cuja liberação tem sido um dos grandes desafios da história do feminismo brasileiro contemporâneo - e suas táticas para abordar o problema.

É necessário considerar que a corrente majoritária do movimento feminista no País, que é a dos direitos, situa-se na linhagem do feminismo internacional do início dos anos 1970, com uma posição favorável à liberação do aborto. ${ }^{1}$ Tal posição se confronta, antes de tudo, com a permanência da proibição legal inscrita no Código Penal brasileiro de 1940, no qual o aborto é considerado crime, salvo em risco de vida da mulher e em gravidez decorrente de estupro. É crime raramente punido, tanto para as mulheres que o realizam como para as parteiras, ou para os médicos que o executam, mesmo com a ocorrência de morte da gestante. ${ }^{2}$ Entretanto, não podemos desconsiderar a força simbólica dessa interdição penal sobre o imaginário social e subjetivo de quem o pratica, já que há notificações policiais, processos penais, enfim, todo um aparato criminal disponível em torno do aborto, mesmo que ele não resulte em condenação. ${ }^{3}$

\footnotetext{
Copyright $\odot 2008$ by Revista Estudos Feministas.

1 Corrente do feminismo centrada nas lutas pelos direitos específicos das mulheres - saúde reprodutiva, sexualidade, educação, trabalho, violência e política - com base no princípio dos direitos individuais do liberalismo democrático. Esta corrente associa os direitos humanos aos direitos sociais, ao considerar as profundas desigualdades sociais que distanciam o País das conquistas feministas já alcançadas nos centros hegemônicos de poder e, portanto, identifica-se com correntes políticas de esquerda. É a corrente política predominante do feminismo hoje no Brasil e em outros países da América Latina; diferencia-se das correntes feministas que privilegiam a luta pela transformação do sistema patriarcal e/ou falocrático, ou ainda daquelas que priorizam a luta contra heteronormatividade.

${ }^{2}$ Daniela ARDAILLON, 1997.

${ }^{3}$ Lucila SCAVONE e Gisele CORTÊS, 2000.
} 
Ao peso da proibição legal acrescem-se os problemas morais, religiosos, subjetivos, de saúde e de gênero/classe/raça relacionados à prática do aborto. Há igualmente que considerar o significado simbólico da interrupção de uma gravidez indesejada, o qual coloca em questão a realização da maternidade, tradicionalmente considerada como marca relevante da identidade histórico-cultural feminina brasileira. Esse quadro dá uma idéia das forças passíveis de compor o jogo das políiticas relativas ao aborto no País, com as diferentes posições de seus autores.

Ao observarmos a história dos debates e das ações políticas feministas em prol da liberalização do aborto no País, constatamos que ela foi marcada por avanços, recuos e, sobretudo, por inúmeras negociações políticas. Da omissão da palavra "aborto", em meados dos anos 70 - para assegurar as alianças políiticas com os setores da esquerda e da lgreja Católica progressista na luta contra a Ditadura -, à opção políitca pela descriminalização e pela efetivação dos casos previstos por lei, o percurso das políticas feministas para tratar do problema indica não só o poder das forças conservadoras em jogo como a vocação política do feminismo brasileiro para a negociação.

Em meados da década de 1970, o feminismo brasileiro já tinha uma posição política sobre o aborto fundamentada no princípio do direito individual. Ao contornar demandas abertas pelo direito ao aborto, as feministas costumavam substituí-las por fórmulas gerais, tais como "direito de decidir pelo número de filhos desejados", "direito de conhecer e decidir sobre seu próprio corpo", entre outras. ${ }^{4}$ Sempre é bom lembrar que a negociação também era feita entre as próprias feministas, pois havia aquelas que, ligadas aos partidos de esquerda ortodoxos, não aceitavam enfatizar a questão do aborto.

Na reputada Carta das mulheres enviada ao Congresso Nacional durante as mobilizações feministas para a redação da nova Constituição de 1988, não há referência direta à questão do aborto, que teria sido substituída por: "será garantido à mulher o direito de conhecer e decidir sobre o seu próprio corpo". Celi Pinto ${ }^{5}$ considera que a ausência da demanda explícita do direito ao aborto nessa carta foi "um recuo tático diante do avanço conservador" que ameaçava modificar a legislação, que já garantia o aborto previsto por lei. No começo dos anos 1980, uma publicação sobre o aborto da Frente Feminista de Mulheres de São Paulo tratava-o como um direito de autonomia e ressaltava os perigos à saúde das mulheres, que decorriam de sua clandestinidade, principalmente, nas camadas populares. ${ }^{6}$ Ali já estavam explícitos dois argumentos políticos que são até hoje utilizados pelo feminismo brasileiro para discutir a legalização do aborto: a questão dos direitos individuais e dos direitos sociais (este apoiado no argumento da saúde/classe social). Além da justeza deste último argumento, ele foi útil para sensibilizar os setores da esquerda que não consideravam prioritária a luta pelo aborto. Essas duas questões aparecem geralmente imbricadas nas argumentações das feministas brasileiras e orientam suas táticas até o presente.

Tratar o aborto como direito social significa questionar as condições precárias em que ele é realizado no País, ao arriscar a saúde e a vida das mulheres. Em consonância com as preocupações das feministas brasileiras dos anos 1980, as feministas dos anos 1990 passaram a considerar a alta incidência de abortos clandestinos no País como um

\footnotetext{
${ }^{4}$ Observam-se essas sutis reivindicações nos primeiros seminários e congressos de mulheres, em meados da década de 1970, no Rio de Janeiro e em São Paulo. Ver: Amélia TELES, 1993; e Leila BARSTED, 1992.

${ }^{5}$ Céli R. PINTO, 2003, p. 76. Maria Isabel Baltar Rocha afirma que a reivindicação ao direito da interrupção da gravidez foi expressa na Carta das mulheres, mas que houve um acordo durante o processo constituinte para não apresentá-la à Assembléia (2006).

${ }^{6}$ Carmen BARROSO e Maria José C. CUNHA, 1980.
} 
problema de saúde pública pela alta mortalidade que Ihe estava associada, ${ }^{7}$ qualificandoo de aborto inseguro. Essa posição foi expandida pelas Conferências do Cairo e de Beijing e reforçou as ligações das estratégias locais e globais.

O aborto como questão de direito individual remete a um dos fundamentos do feminismo contemporâneo: o princípio democrático liberal do direito aplicado ao corpo; direito baseado nas idéias de autonomia e liberdade do liberalismo, expresso na máxima feminista "nosso corpo nos pertence", que se difundiu internacionalmente a partir dos países centrais e marcou as lutas feministas relacionadas à sexualidade, à contracepção e ao aborto. A apropriação do corpo também significava para as mulheres a possibilidade da livre escolha da maternidade. No caso brasileiro, essa influência foi clara no início do feminismo contemporâneo (1970/85) e, posteriormente, será ressignificada na adoção do conceito de direitos reprodutivos, a partir de meados dos anos 1980.

A noção de direitos reprodutivos propagou-se no feminismo brasileiro a partir da sessão do Tribunal Internacional de Saúde e Direitos Reprodutivos, no I Encontro Internacional de Saúde da Mulher, em Amsterdã, em 1984. Ela foi acatada pelo grupo de brasileiras ali presentes e, em seguida, "incorporada à linguagem feminista" uma década antes de ter sido "consagrada nas conferências do Cairo e de Beijing". A utilização desse conceito no contexto da redemocratização do País teve um êxito considerável por se tratar de um novo modo de abordar os problemas de saúde das mulheres, até então, considerados como "circunscritos à natureza, ao pecado, à vontade divina ou ao poder dos médicos" e dos legisladores. ${ }^{8}$ Considerar esse direito na perspectiva da expansão dos direitos humanos como é tido pela corrente feminista brasileira dos direitos - é aceitar sua ascendência nos direitos individuais que nos remete à apropriação do próprio corpo.

Em 1989 no Encontro Nacional Saúde da Mulher, um Direito a ser Conquistado, organizado pelo Conselho Nacional dos Direitos da Mulher (CNDM), no Rio de Janeiro, há uma demanda pela descriminalização do aborto com base no argumento mais amplo dos direitos, explícito no próprio título do evento. ${ }^{9}$ A Carta das mulheres em defesa de seu direito à saúde, documento final desse encontro, considera inicialmente o aborto como "um problema de saúde da mulher" e demanda a "imediata revogação de todos os artigos do Código Penal que definem o aborto como crime", lembrando que, na (então, nova) Constituição de 1988, a saúde passou a ser considerada como um direto de todos e um dever do Estado. Ao considerar que as mulheres tinham "o direito de interromper a gravidez", essa carta lembrava aos legisladores que um direito individual não podia ser tratado como crime. ${ }^{10}$

Portanto, ao constatar que vários segmentos da sociedade não apoiavam a criminalização do aborto, mesmo que eles o condenassem moralmente, o feminismo brasileiro considerou que essa seria a melhor tática política para sensibilizar setores progressistas da sociedade, antes silenciosos sobre a questão. Ela se constituiu em uma

\footnotetext{
${ }^{7}$ Segundo estimativas do Instituto Alan Guttmacher em 1991 ocorriam entre 700 mil e 1,4 milhão de abortos clandestinos no país. Em 1998, o aborto (provocado e espontâneo) era a quarta causa da mortalidade materna no país (REDESAÚDE, 2001).

${ }^{8}$ Sônia CÔRREA e Maria Betânia ÁVILA, 2003, p. 26-27.

9 O CNDM em sua primeira gestão (1985-1989) estava ligado ao Ministério da Justiça e tinha estrutura deliberativa e executiva, semelhante a uma Secretária de Estado, o que não ocorreu nas gestões seguintes. Em 2003, o CNDM passou a integrar a nova Secretaria Especial de Políticas para as Mulheres (SPM).

10 Os termos desta carta estão reproduzidos no artigo de: BARSTED, 1992, p. 123-124. Esta carta pode ser considerada como um dos manifestos inaugurais das políticas feministas do aborto, pois ali já estão contidas as principais estratégias do feminismo brasileiro em relação à luta por sua liberação.
} 
lógica argumentativa com poder de convencimento, apoiada no princípio genérico do direito individual e reforçada pelos impactos políticos das conferências internacionais.

De fato, nos anos 1990, o movimento já não estava tão solitário nessa luta, contou com a adesão crescente de novos segmentos sociais: profissionais de saúde, juristas e parlamentares, com os quais o movimento estabeleceu amplo diálogo. Foi o período em que houve maior número de projetos de lei relacionados ao aborto no Congresso Nacional - com posições favoráveis, desfavoráveis e intermediárias -, evidenciando o crescimento democrático do debate." Entretanto, o argumento da descriminalização até o presente não logrou sensibilizar amplas camadas da população.

Outra tática do movimento feminista foi demandar garantia do direito aos casos previstos por lei (risco de vida da mulher e gravidez decorrente de estupro), que permitia, sobretudo, realizar o que já estava legislado. Interessante verificar que a Carta de 1989 citada mencionava esse direito das mulheres e, sobretudo, o dever do Estado de garanti-lo. Se de um lado a realização desse tipo de aborto nos serviços públicos de saúde tem se ampliado, ela só foi instituída efetivamente em um hospital público a partir de 1989, pela Prefeita de São Paulo (Luiza Erundina), 49 anos depois de ser reconhecida no Código Penal. ${ }^{12}$

O feminismo tem centrado sua luta na garantia da aplicação dessa lei especialmente nos interlúdios da batalha maior pela descriminalização e legalização -e buscado ampliá-la para outros casos. Destaca-se o grupo das Católicas pelo Direito de Decidir (CDD), pois constitui uma oposição importante no seio da própria Igreja Católica, a qual tem sido tradicionalmente uma força importante contra a legalização do aborto no País. Cabe lembrar que a ameaça da retirada dos dispositivos legais existentes paira até o presente no discurso conservador, que também dificulta a sua ampliação.

Bila Sorj ${ }^{13}$ considera que a "estratégia discursiva" do feminismo está enraizada na "cultura política" brasileira com forte tendência - histórica, diga-se de passagem - a evitar conflitos e procurar saídas conciliatórias. Embora concorde com a autora no que diz respeito à política conciliatória, não concordo quando considera essa estratégia desligada do princípio dos direitos individuais. Isto porque ao lutar pela garantia do que já está assegurado por lei - e para o Estado oferecer esses serviços pelo País afora - o feminismo realiza simbólica e materialmente um ato de afirmação do direito individual de escolha da maternidade, mesmo que ele seja restritivo.

Não querer ter um/a filho/a decorrente de um ato violento como o estupro é um direito individual já garantido por lei que deve ser assegurado. Retomam-se aqui as idéias já presentes no feminismo brasileiro dos anos 1980, conforme relatado. Entretanto, paira no ar a dúvida de que lutas parciais, como essa, impossibilitem ou retardem uma luta mais radical que proponha frontalmente uma ampla legalização do aborto, o que de qualquer maneira não invalida a importância do que já está sendo feito.

Em 2005 a Primeira Conferência Nacional de Políticas Públicas para as Mulheres afirmou a existência de um estado laico e recomendou a revisão da criminalização do aborto, reutilizando esse argumento fundamentado nos direitos individuais. A SPM designou uma comissão tripartite, com representantes do Executivo, Legislativo e Sociedade Civil

\footnotetext{
${ }^{11}$ Maria Isabel B. ROCHA e Jorge A. NETO, 2003.

${ }^{12}$ Cabe lembrar que este atendimento foi iniciado em um hospital do Rio de Janeiro na década de 1980, mas não teve continuidade, e também que a deputada estadual pelo Rio de Janeiro Lúcia Arruda (PT/RJ) conseguiu a aprovação da AL do Rio de Janeiro ao atendimento dos casos previstos por lei na rede pública em 1985; a lei foi logo revogada. BARSTED, 1992, p. 120-124.

${ }^{13}$ Bila SORJ, 2002, p. 102-103.
} 
(inclusive feministas), para discutir a questão do aborto. Essa comissão elaborou um projeto preliminar de descriminalização e legalização do aborto que foi enviado ao Congresso em 2006 e ainda aguarda votação. A lenta tramitação de projetos polêmicos no Congresso é usual, entretanto, a conjuntura política nacional da época em que ele foi enviado estava afetada pela mais grave crise política do governo Lula, o que retardou sua tramitação mesmo após passada a crise..$^{14}$

No final de 2007, o governo lançou o Programa Especial de Planejamento Familiar, buscando contornar o problema do aborto, e foi apoiado por um grupo de feministas. Entretanto, esse grupo aproveitou a ocasião para manifestar os princípios feministas do estado laico, dos direitos reprodutivos, da questão do aborto inseguro e da afirmação do projeto de descriminalização. Observa-se, então, que o feminismo insere habilmente a questão do aborto na discussão mais abrangente dos direitos sexuais e reprodutivos e afirma não só os compromissos do País nas convenções internacionais sobre o tema como o projeto de lei enviado ao Congresso. ${ }^{15}$ Evidentemente, o alcance desse posicionamento é mais político do que social.

A análise desta pequena trajetória reforça a tese sobre a habilidade da corrente do movimento feminista brasileiro que vem lutando para descriminalizar o aborto - aqui denominada dos direitos - para negociar soluções e fazer alianças políiticas bem-sucedidas com os setores progressistas da sociedade. Um dos pontos fracos das políticas feministas do aborto tem sido a impossibilidade material e simbólica de atingir um público maior, já que o filtro dos meios de comunicação e das instituições educacionais e religiosas na maioria das vezes evita ou amaldiçoa o tema. Entretanto, a cada possibilidade de liberação do aborto as forças conservadoras contra-atacam, cada vez com maior agressividade, cooptando a opinião pública favoravelmente. Esse é um desafio a ser enfrentado pelas feministas brasileiras empenhadas nessa luta, o que nos leva a concluir que essas negociações tiveram mais êxito em nível político do que social, pois não lograram alcançar e sensibilizar camadas mais amplas da população.

\section{Referências bibliográficas}

ARDAILLON, Daniela. "O lugar do íntimo na cidadania de corpo inteiro". Revista Estudos Feministas, Rio de Janeiro: IFCS/UFRJ, v. V, n. 2, p. 376-388, 1997.

BARROSO, Carmen; CUNHA, Maria José C. O que é o aborto, frente de mulheres feministas. São Paulo: Cortez, 1980.

BARSTED, Leila A. L. "Legalização e descriminalização do aborto no Brasil, 10 anos de luta feminista". Revista Estudos Feministas, Rio de Janeiro: CIEC/ECO/UFRJ, n. 0, p. 104-130, 1992.

CARTA do Rio de Janeiro, pelos Direitos Sexuais e Reprodutivos, pela Eqüidade de Gênero e em Defesa do Estado Laico. 24 ago. 2007. Disponível em: www.petitiononline.com/ cartario . Acesso em: 12 set. 2007.

CÔRREA, Sônia; ÁVILA, Maria Betânia. "Direitos sexuais e reprodutivos. Pauta global e percursos brasileiros". In: BERQUÓ, E. (Ed./Dir.). Sexo \& vida. Panorama da saúde reprodutiva no Brasil. Campinas: Unicamp, 2003. p. 17-78.

\footnotetext{
${ }^{14}$ Crise política na qual o governo foi acusado de fornecer um pagamento mensal a parlamentares para apoiar a votação de suas emendas no Congresso; foi denominada por políticos e pela mídia de mensalão. Quando as acusações vieram à tona, ministros caíram e o governo teve que recompor sua liderança política. Nesse contexto, um projeto tão polêmico como o da legalização do aborto não tinha condições de tramitar no Congresso.

${ }^{15}$ CARTA..., 24 ago. 2007.
} 
PINTO, Céli R. J. Uma história do feminismo no Brasil. São Paulo: Perseu Abramo, 2003.

REDESAÚDE. Dossiê aborto inseguro. São Paulo: Rede Nacional Feminista de Saúde e Direitos Reprodutivos, 2001.

ROCHA, Maria Isabel Balthar. "A discussão política sobre o aborto no Brasil: uma síntese". Revista Brasileira de Estudos de População, São Paulo, v. 23, n. 2, p. 169-174, jul. 2006. ROCHA, Maria Isabel Balthar; NETO, Jorge A. "A questão do aborto: aspectos clínicos, legislativos e políticos". In: BERQUÓ, E. (Ed./Dir.). Sexo \& vida. Panorama da saúde reprodutiva no Brasil. Campinas: Unicamp, 2003. p. 257-337.

SCAVONE, Lucila; CORTÊS, Gisele. "Do subjetivo ao social: implicações sociológicas do aborto". In: SCAVONE Lucila; BATISTA Luis Eduardo (Orgs.). Pesquisas de gênero: entre o público e o privado. Araraquara: Laboratório Editorial/UNESP, 2000. p. 43-55.

SORJ, Bila. "O feminismo e os dilemas da sociedade brasileira". In: BRUSCHINI, C.; UNBEHAUM, S. Gênero, democracia e sociedade brasileira. São Paulo: FCC/Editora 34, 2002. p. 98107.

TELES, Maria Amélia. Breve história do feminismo no Brasil. São Paulo: Brasilense, 1993. p.117-119.

[Recebido em maio de 2008 e aceito para publicação em junho de 2008]

\section{The Gender Pollitics of Abortion}

Abstract: The debates and feminist actions in favor of the legalization of abortion in Brazil were characterized by progresses and regressions, and above all by countless political negotiations. From the omission of the word "abortion", in the mid-seventies, to the political choice of decriminalization and application of the cases foreseen by law, Brazilian feminism has been marked by the choice of negotiation. The article concludes that these negotiations have succeeded politically but failed to reach society and heighten public awareness at a large scale.

Key Words: Abortion in Brazil; Feminism and Abortion; Individual Rights and Abortion; Legalization of Abortion; Feminism and Politics. 